\title{
A MUTATION OF MITOCHONDRIAL DNA IN JAPANESE FAMILIES WITH LEBER'S HEREDITARY OPTIC NEUROPATHY
}

\author{
Keiko Fujiki, ${ }^{1}$ Yoshihiro Hotta, ${ }^{1}$ Mutsuko Hayakawa, ${ }^{1}$ Kimiko Saito, ${ }^{1}$ \\ Fumino ArA, ${ }^{1}$ Syunsuke UedA, ${ }^{1}$ Toshiko Goto, ${ }^{1}$ Misako IsHIDA, ${ }^{2}$ \\ Kenji Yanashima, ${ }^{2}$ Takashi Shiono, ${ }^{3}$ Jo SaKaI, ${ }^{4}$ Atsushi KanaI, ${ }^{1}$ \\ and Akira NAKAJIMA ${ }^{\mathrm{l}}$ \\ ${ }^{1}$ Department of Ophthalmology, Juntendo University School of Medicine, \\ Bunkyo-ku, Tokyo 113, Japan \\ ${ }^{2}$ National Rehabilitation Center for the Disabled, \\ Tokorozawa, Saitama 359, Japan \\ ${ }^{3}$ Department of Ophthalmology, Tohoku University School of Medicine, \\ Aoba-ku, Sendai 980, Japan \\ ${ }^{4}$ Department of Ophthalmology, Kobe University School of Medicine, \\ Chuo-ku, Kobe 650, Japan
}

\begin{abstract}
Summary Leber's hereditary optic neuropathy (LHON) is a maternally inherited disease characterized by optic nerve degeneration associated with severe bilateral visual loss in young men and occasionally in women. A mitochondrial DNA (mtDNA) replacement mutation in LHON patient, $\mathrm{G}$ to A transition at nucleotide position (nt) 11778 converting the 340 th arginine to histidine in the NADH dehydrogenase subunit 4 , was detected as SfaNI site polymorphism (Wallace et al., Science, 242: 1427-1430, 1988). To evaluate if the $S f a$ NI site loss can be used to diagnose LHON patients, mtDNAs from peripheral blood of six affected males including five probands from five unrelated Japanese families with LHON, a pair of parents and a normal sister of one of the probands and 4 control persons were analyzed using PCR amplification method. The mutation of leukocyte mtDNA at nt 11778 was identified in all of the affected patients, the normal mother and the sister examined, while the father who is normal and 4 control persons did not show the change. These findings support that the mutation at nt 11778 is also associated with LHON in the Japanese and the test of the SfaNI site loss described here is useful for confirming the clinical diagnosis of LHON patients with the mutation at nt 11778.
\end{abstract}

Key Words mitochondrial DNA, Leber's hereditary optic neuropathy, maternal inheritance, point mutation, PCR

Received, August 20, 1990; revised version received February 18, 1991; Accepted February 25, 1991. 


\section{INTRODUCTION}

Leber's hereditary optic neuropathy (LHON) is a maternally inherited disease characterized by optic nerve degeneration associated with severe, bilateral visual loss in young men and occasionally in women. LHON patients have been found to be related exclusively through the maternal lineage (Imai and Moriwaki, 1936; Nikoskelainen et al., 1987). The human mitochondrial DNA (mtDNA) is also maternally inherited (Giles et al., 1980).

A mtDNA replacement mutation, $G$ to $A$ transition at nucleotide position (nt) 11778 converting the 340 th arginine to histidine in the NADH dehydrogenase subunit 4 , detected as a $S f a \mathrm{NI}$ site polymorphism, was identified in nine of $11 \mathrm{LH}$ ON families by Wallace et al. (1988). Arginine is highly conserved among various species, being present in identical positions in the proteins (Bibb et al., 1981; Anderson et al., 1982). The same mutation detected as the SfaNI site polymorphism has been identified in Japanese LHON families (Yoneda et al., 1989, 1990; Hotta et al., 1989; Mashima et al., 1989).

In the present study, to evaluate if the $S f a$ NI site loss can be used to diagnose LHON patients, the mtDNAs from peripheral blood of six affected males including five probands from five unrelated Japanese families with LHON, a pair of parents and a sister of one of the probands, and 4 normal persons were analyzed using the polymerase chain reaction (PCR).

\section{MATERIALS AND METHODS}

The study was based on five Japanese families (families A-E) with LHON. In family A (Fig. 1), an affected brother, a clinically normal sister and normal parents of the proband were studied. In each of the other four families, only an affected. proband was available for the examination, where the proband of family $\mathrm{B}$ has an affected brother and two affected maternal uncles; the proband of family $\mathrm{C}$ has an affected maternal grandmother's brother and maternal sister's son; the proband of family $\mathrm{D}$ has an affected brother and two affected nephews who are sister's sons of the proband; and family $\mathrm{E}$ has no affected person other than the proband. Four independent normal controls were also tested.

Leukocyte pellets of these members were isolated from $10 \mathrm{ml}$ of peripheral blood. The mtDNA was obtained from the pellets with the Hirt's method (Hirt, 1967). A 24 mer sense primer oligonucleotide with ATTCTCATCCAAACCCCCTGAAGC, corresponding to the sequence between 11660 and 11683 bases, and a 24 mer antisense primer with GAGAACGTGGTTACTAGCACAGAG between 11896 and 11919 bases of mtDNA were prepared using a DNA synthesizer (Applied Biosystems, Foster city, CA). About $100 \mathrm{ng}$ DNA was amplified by a DNA amplification system (Perkin Elmer Cetus, Emeryville, CA). After DNA purifica- 


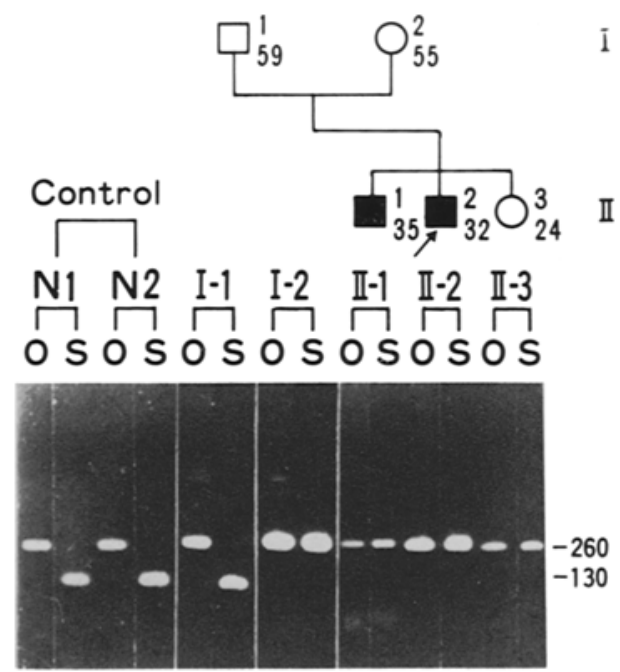

Fig. 1. Electrophoresis patterns of the wild-type $(130 \mathrm{bp})$ and the mutant $(260 \mathrm{bp}) \mathrm{mtDNA}$ digested with $S f a \mathrm{NI}$ in family A. N1 and N2, normal control individuals; O, original DNA amplified by PCR; S, DNA digested with SfaNI.

tion, 260 bp fragment DNAs were digested by a restriction enzyme SfaNI (New England Biolabs, Beverly, MA) and FokI (Takara Biomedicals, Kyoto). The samples underwent electrophoresis on $2 \%$ agarose gel. The 123 bp DNA ladder (Bethesda Research Laboratories, Gaithersburg, MD) was used as a DNA size marker. Patterns of digestion by FokI identified amplified fragments and confirmed the DNA quality.

\section{RESULTS}

Figure 1 shows electrophoresed DNAs from the members of family A and from normal control individuals. A $260 \mathrm{bp}$ fragment corresponds to the nucleotides between nt 11660 and 11919 in the wild-type mtDNA. The nt 11778 of the wildtype mtDNA is a recognition site of $S f a$ NI. Therefore, SfaNI cuts the wild-type mtDNA to approximately 130 bp DNA doublets, while the mtDNA with the transition of nucleotide at this site is not digested. The $130 \mathrm{bp}$ bands were detected in all the four control individuals and the father (I-1), but no SfaNI site was found in the proband (II-2), the affected brother (II-1), the normal sister (II-3) and the mother (I-2). Likewise, the other four patients of the four unrelated families did not show the $130 \mathrm{bp}$ fragments.

\section{DISCUSSION}

The nt 11778 mutation discovered by Wallace et al. (1988) was detected in all 
of the five families examined. Identical mutation has been found in other Japanese families (Yoneda et al., 1989, 1990; Mashima et al., 1989). These findings may suggest that the nt 11778 mutation is highly prevalent in Japanese LHON, though more families should be tested. On the other hand, Holt et al. (1989) and Vilkki et al. (1989) reported that LHON is a genetically heterogeneous disorder and about $50 \%$ of cases of definite LHON are due to the nt 11778 mutation. More cases need to be studied to determine this point. The mutation induced by common ancestor might have been preserved for a long time because the Japanese population had formed a closed society for geographical and social reasons. The detection of the nt 11778 mutation is very useful for the diagnosis of LHON especially in Japanese.

The normal mother and sister of proband have lost SfaNI site in family A. Although they are 55 and 24 years old and may develop the disease, they are at present only carriers. A strong male bias and the occasional appearance of symptoms in females cannot be explained by a single mtDNA defect alone. It seems that additional factors are involved in the expression of the mutant phenotype. Recently, a variable mixture of the mutant and wild-type mtDNA (heteroplasmy) was reported in LHON families (Holt et al., 1989; Lott et al., 1990). The relative proportion of mutant and wild-type mtDNA may be correlated with the risk of developing LHON. Further study is required to clarify the mechanism of the disease. To check the SfaNI site loss, nevertheless, is useful to diagnose LHON with nt 11778 mutation, because clinical diagnosis of LHON is often difficult.

Acknowledgment This work was supported in part by the Grant-in-Aid for Scientific Research (No. 01480420) from the Ministry of Education, Science and Culture of Japan.

\section{REFERENCES}

Anderson, S., Bruijn, M.H.L., Coulson, A.R., Eperon, I.C., Sanger, F. and Young, I.G. 1982. Complete sequence of bovine mitochondrial DNA conserved features of the mammalian mitochondrial genome. J. Mol. Biol. 156: 683-717.

Bibb, M.J., Etten, R.A.V., Wright, C.T., Walberg, M.W. and Clayton, D.A. 1981. Sequence and gene organization of mouse mitochondrial DNA. Cell 26: 167-180.

Giles, R.E., Blanc, H., Cann, H.M. and Wallace, D.C. 1980. Maternal inheritance of human mitochondrial DNA. Proc. Natl. Acad. Sci. U.S.A. 77: 6715-6719.

Hirt, B. 1967. Selective extraction of polyoma DNA from infected mouse cell culture. J. Mol. Biol. 26: 365-369.

Holt, I.J., Miller, D.H. and Harding, A.E. 1989. Genetic heterogeneity and mitochondrial DNA heteroplasmy in Leber's hereditary optic neuropathy. J. Med. Genet. 26: 739-743.

Hotta, Y., Hayakawa, M., Saito, K., Kanai, A., Nakajima, A. and Fujiki, K. 1989. Diagnosis of Leber's optic neuropathy by means of polymerase chain reaction amplification. Am.J. Ophthalmol. 108: 601-602.

Imai, Y. and Moriwaki, D. 1936. A probable case of cytoplasmic inheritance in man: a critique of Leber's disease. J. Genet. 33: 163-167.

Lott, M.T., Voljavec, A.S. and Wallace, D.C. 1990 . Variable genotype of Leber's hereditary optic neuropathy, patients. Am. J. Ophthalmol. 109: 625-631. 
Mashima, Y., Oguchi, Y., Uemura, Y., Kudo, J., Sakai, K., Shimizu, N. and Hotta, Y. 1989. DNA diagnosis of Leber's optic neuropathy. Ganka (in Japanese) 31: 1043-1048.

Nikoskelainen, E.K., Savontaus, M.-L., Wanne, O.P., Katila, M.J. and Nummelin, K.U. 1987. Leber's hereditary optic neuroretinopathy, a maternally inherited disease. Arch. Ophthalmol. 105: 665-671.

Vilkki, J., Savontaus, M.-L. and Nikoskelainen, E.K. 1989. Genetic heterogeneity in Leber hereditary optic neuroretinopathy revealed by mitochondrial DNA polymorphism. $A m$. $J$. Hum. Genet. 45: 206-211.

Wallace, D.C., Singh, G., Lott, M.T., Hodge, J.A., Schurr, T.G., Lezza, A.M.S., Elsas, L.J., II and Nikoskelainen, E.K. 1988. Mitochondrial DNA mutation associated with Leber's hereditary optic neuropathy. Science 242: 1427-1430.

Yoneda, M., Tsuji, S., Yamauchi, T., Inuzuka, T., Miyatake, T., Horai, S. and Ozawa, T. 1989. Mitochondrial DNA mutation in family with Leber's hereditary optic neuropathy. Lancet i: $1076-1077$.

Yoneda, M., Tsuji, S., Yamauchi, T., Inuzuka, T., Miyatake, T., Abe, H., Horai, S. and Ozawa, T. 1990. Mitochondrial DNA mutation in families with Leber's hereditary optic neuropathy. Jpn. J. Human Genet. 35: 50. 